\title{
(B) Hortrations
}

ON

\section{THE MIDWIVES ACT AND THE TEACHING OF MIDWIFERY TO STUDENTS.}

Being Part of the Presidential Address delivered before the Yorkshire Branch of the British Medical Association.

By CHARLES J. WRIGHT, M.R.C.S.ENG., L.S.A., Professor of Obstetrics, University of Leeds ; Senior Surgeou, Hospital for Women and Children, Leeds.

Doring the year 1902 an Act of Parliament became law which at least makes us feel that we are not now the only civilized country without some sort of State regulation to control the wholesale disaster in the practice of those who style themselves "midwives." The Midwives Act, as we know, has for years given rise to much controversy in the profession; in fact, to the discussion and want of accord which existed we may attribute the fact that the Bill was not made better than it is.

Whatever may be the views of the members of this Branch on the question-and I think events have already proved that the fears of the opponents were to some extent groundless-we may, I think, now do our best to face the situation and to work for the common weal. My own feeling has been for many years that nothing could well be worse than the condition of things as it has existed, and that consequently whatever was done must necessarily ten $t$ towards improvement, and that compulsory powers through Act of Parliament were not only necessary but imperative to prevent the dire results of obstetric practice by wholly incompetent females, whose only title to spread broadcast disease and death was desire to earn a living on the strength of probably nothing but the personal experience of having had one or more children herself, with possibly-but by no means invariably-the additional experience of tending to the wants of a lying-in friend or neighbour. Our hospital out-patient departments are daily producing examples of the results of want of foresight and attention during labour, and of care and direction during the puerperal period. When the question is put: " Had you a doctor for your confinement?" the usual answer is "No, I had a woman," or, "Only a doctor when too late for treatment." The undiminished mortality from puerperal disease has been graphically described by Dr. Cullingworth, not only in the country districts, but in the poorer districts of the large cities, especially of London. The deaths from the "accidents of childbirth," as shown by the RegistrarGeneral's returns, point to a condition of things which must be remediable, and by what other means can it be remedied than by legislation enforcing proper training?

See what enactment has done in Italy, where ${ }^{1}$, as in many Continental countries, midwives are in far more general use than in Great Britain. The law of Government supervision was passed nearly thirty years ago. Obstetric schools have been instituted, and training for two years in an extern maternity, or one year and eight months in a maternity hospital required. Special regulations and instructions were issued in 1890. In 1887 there had been 2,504 deaths from puerperal fever, and 4,436 from other diseases of parturition and the puerperium, equivalent to 85 and 130 respectively to every million inhabitants. In 1902 the number amounted to 32 and 53 respectively, or a total of 85 per million, as compared with the 235 of the former decade. Yet the figures in our own country remain much the same as heretofore. The total deaths from puerperal fever and the accidents of childbirth amount, on an average for the last three decades, to 4.7 per 1,000 births-a large proportion indeed.

Taking the average of 54 years, in the West Riding of Yorkshire they were 2. I and 2.9 per 1.000 births respectively, or a total of 5 per mille. In South. Wales they reached a higher proportion-2.2 and 3.7, or 5.9 per 1,000. One year-1893-the general average was 6.51 , the highest on record since registration was commenced. As Dr. Williams, Medical Officer of Health for Glamorganshire, has recently pointed out in his Milroy lectures, it is remarkable how the mortality from puerperal fever - as shown by the Registrar-General's returnshas remained without diminution for many years, and that in spite of the advances of aseptic and antiseptic precautions, and the better equipment of maternity hospitals and charities. We look upon "puerperal sepsis" as a preventable disease and the "accidents of childbirth" as controllable. "If then," as Dr. Williams asks, "preventable, why not prevented?"2

Let us, then, by every means in our power, give the existing law our support, if not our entire approval. We may not all agree as to the best means to obtain our ends. An ideal is generally unattainable, and the Act may fall far short of what many have desired; but it is at least an attempt to do something. The Central Midwives Board is a strangely-constituted body. Its members are, no doubt, in earnest in an endeavour to act each from their own point of view, and may, in course of time, wipe out the untrained and uneducated commodity which has worked so much havoc in times gone by. But what a curious combination is this Board, consisting of nine members, of whom three must be non-medical women. Four out of the nine now are non-medical members. No wonder that some of their decisions are the result of incongruous majorities, as has been recently pointed out. ${ }^{3}$ As was the case wich the Dentists Act, and, I presume, with the Medical Act of 1815 , provision has to be made for those who have been some years practising as so-called midwives; but as years roll on these will gradually drop out and be superseded by those who have at least soce training. ${ }^{4}$ The last return of those claiming recognition from being in "bona-fide practice, July, 1901," was 2,928. A minimum of three months" training is, indeed, absurdly small, and the absence of a general nurses' training will, I think, be felt more and more as time goes on; but if we cannot get all we think necessary, we must be thankful that at least a beginning has been made

The new enactment, whilst carefully directing the Centra Midwives Board to note the cases to which medical aid must be called, and "to regulate, supervise, and restrict within due limits the practice of midwives," has somewhat characteristically omitted altogether to note how and by whom the aid of a registered practitioner is to be paid for Certainly practitioners cannot be expected to attend an urgent summons, and without even the usual obstetric notice, without at least some guarantee that they will be remunerated. Probably the local supervising authorities, who are organizing the lists of midwives, will confer with the Central Midwives Board as to some means of providing adequate sums for carrying out the Act. Section Xv of the Act provides that "Any expense under this Act, payable by the Council of the County or County Borough, shall be defrayed out of the county fund or borough rate, as the case may be." Although this obviously, by the section which precedes it, is providing for the legal expenses for prosecution, etc., why should it not be utilized for medical expenses? I am told, however, on good authority that legal opinion has ruled that it cannot, and that nothing short of a new Act of Parliament-a Midwives Amendment Act-can supply this singular omission.

We have in Leeds within the last few weeks been able to remove a blot upon our city by providing in the new buildings of the "Hospital for Women and Children" a small maternity department. Hitherto, Leeds was one of the few large cities of England where no maternity hospital for poor lying-in patients existed. It is significant how few of these do go to the workhouse, where no voluntary provision is made. from figures which Dr. Allan has kindly supplied to me, I find that during five years-1898 to 1902 - there were an average of only 80 cases confined in the Leeds Union Workhouse. Of these 80 only 29.4 per cent. were married women, the other 70.6 being unmarried. I am pleased to feel that in our New Hospital for Women we have been able to isolate a department for this purpose, and to equip five beds for cases of urgency and anticipated difficulty, and for other cases so far as accommodation permits. This is very far short of what was originally intended, but it is at least a beginning. If more is needed, it merely rests with the public to provide what our original plans included, a sepurate building with a much larger number of beds. The honorary medical staff cordially invite inspection and criticism of their arrangements. It may at present seem like a castle in the air, but we live in hopes that at no very distant future we may combine with our intern arrangements an extern maternits district, and that they may prove useful to one another ; that we may, in Leeds, be able to provide the necessary training for midwives, who may possibly be enabled to call upon a staff of medical officers, one or two to each district, who might have an honorarium attached to their office, the arrangement being self-supporting the honorary medical staff of the hospital being called upon in case of need.

But, while doing our best to protect from the perils of labour those who cannot obtain, at first hand, the services of 
a qualified practitioner, by educating, controlling, and supervising the midwives of the future, let us inquire whether the present arrangements for the teaching of obstetrics to our medical practitioners of the future is all that we can desire. As a teacher of this branch of medicine of twenty years standing, I may say at once unhesitatingly and emphatically that it is not. I entirely agree with my "Victoria" colleague, Professor Sinclair, ${ }^{4}$ who said recently in an admirable lecture, that "in England, at all events, the instruction of the medical student in practical midwifery remains simply deplorable," and is still a "most prominent defect in the medical education of the country." As members of a powerful Association, representing the bulk of the general practitioners of the British Empire, we are-or ought to be-all directly interested in this subject. Let us inquire what is the present position. and whether it can in the near future be in auy way improved for the benefit of the community at large.

The regulations of the Examining Boards, which naturally guide a man, are most uneven, as the facilities for carrying them out vary widely in the diffesent centres of medical education. Lectures, practical demonstrations, tutorial and conversational classes and theoretical teaching, combined with the use of excellent textbooks, are useful in part; but they should, as is the case in medicine and surgery, be combined with systematic bedside clinical teaching, with the aid of ripe experience. Imagine for a moment the vosition of things if medicine and surgery were taught in the same way as midwifery in our hospitals, by attending on out-patients, or on a limited number of patients in their own homes; the whole occupping a period of one month, sometimes less, of a student's long curriculum! Yet, our examining bodies are sending forth into practice, probably in a country district, miles away from skilled help, men who have attended just a few cases of labour, often all more or less normal, and who have their practical experience and the clinical details of abnormality to learn after they get into practice. They are well taught, by bedside training, the intricate phases of clinical medicine and surgery, and spend time upon the elaborate details of rare and interesting medical and surgical cases which they may hardly ever see again; or, if they do, have generally time to obtain the help of experts in case of need. Yet these men-the practitioners of the future-receive diplomas licensing them to practise, who may be face to face, single-handed, with the gravest case of obstetric danger and difficulty during the first twenty-four hours after putting up their door-plate.

As a University Examiner, I have often been impressed with the want of knowledge of clinical facts evinced by candidates, and I have been painfully conscious that it is not altogether their own fault. Practitioners, too, who employ as locum tentns a newly-fledged M.B. feel, I know, how imperfect he is in his means of treating an ordinary case, say, of abortion or abnormal labour. Our own University regulation (Victoria) is that a candidate for the final M.B. must show evidence of

(x) Having attended during three months the indoor practice of a lying-in hospital, or $(2)$ of having attended not less than twenty cases of labour, at least five of which shall have been conducted under the direct supervision of a registered practitioner, and of having continued such attendance throughout the puerperal period.

If he can have the first, nothing is better; it is the ideal training which very few obtain. The second alternative is painfully unequal and insufficient.

In our own infirmary extern maternity a student has to give a month to getting in at least twenty labours, which of ten include hardly anything but normal cases, a certain number, I fear not too many of which, are supervised by the resident obstetrical officer (a recently-qualified man at the infirmary) so far as his time and opportunity will permit.

At Edinburgh University, owing to the number of candidates being far in excess of the number of labours available twelve cases only are enjoined. Two students attend a case with two nurses, the latter being sometimes perhaps the better able of the two to meet the necessities of the case! Of course some enter for the practice of the maternity hospital, or go to the Rotunda at Dublin, where the clinical teaching is notoriously the best that can be obtained.

At a hospital with maternity beds in a neighbouring city I am told that for the twenty cases seen by each student the average attendance at the hospital is " under a fortnight "namely, four or five in hospital and fifteen to sixteen outside. remember the time when our own students had to go to Manchester and there be conducted by female midwives to see their cases, and I was thought to be somewhat revolutionary when, as Secretary to our old Leeds School of
Medicine, I suggested that some provision for them might be attempted here. This was in 1879 , six years before the extern maternity charity at the infirmary was matured. I trust that the day is not far distant when there will be opportunities for every student to see the in-patient and out-patient practice of a lying-in hospital, as they do now at the Rotunda in Dublin, in Queen Charlotte's Hospital in London, and at other hospitals.

Opportunities will be too limited here to attempt much for some time, but sooner or later it must come. Sheffield has already a notable provision in its new Jessop Hospital of fifty maternity beds. Birmingham, like Leeds, has hitherto been without, but hopes soon to possess some accommodation for lying-in cases. In London, the magnificent Guy's Maternity Charity, where I first attended midwifery. has recently added a maternity department of seven or eight beds for in-patients, and University College hopes to do the same ere long. Other hospitals are organizing a department with a ward for the diseases of pregnancy. But I hear it whispered that we must not throw open our wards in a semi-private hospital to students. Then, may I ask, how are the practitioners of the future, who are to tend and preserve the perineums and the lives of the coming generation, to be rendered capable of doing credit to their Alma Mater? There will, no doubt. be objections and difficulties, and we must at present mark time as to this somewhat delicate point, but it must ere long be faced boldly and fearlessly as a crying need of public importance.

I am aware that my protest is by no means new. In 1896 Dr. Herman wrote an able article in the Practitioner, ${ }^{5}$ deploring the imperfect methods of teaching in London and elsewhere, and quoting the astonishment of Professor August Martin, of Griefswald, at what he had noticed during a visit to this country. The teaching of obstetrics in many Continental universities shows how far behind them we are in the methods of training and systematic detailed teaching. America also is trying now to remedy this grave defect in teaching. Quite recently, too, my friend and colleague, Professor Sinclair, has enlarged upon this theme with unflinching and characteristic vigour in an address to the students at Owens College. Since, too, much of the above was written, I have seen some uble remarks on similar lines by Dr. Hellier, ${ }^{6}$ who recognizes the same want, and who will, $I$ know, aid me in my efforts to improve our system here.

As for a present way to meet the difliculty, I give $\mathrm{Dr}$. Herman's own words in the article to which I have referred.

I suggest that an officer (or officers, according to the number of patients and of students) should superintend the outdoor maternity charity and teach midwifery practically to students. He should give his whole time to this work, and should receive sufficient direct remu neration to make the post attract a capable man. This officer should go to each case with the student appointed to attend it. He should let the student perform every manipulation, showing him how to do it, and then should correct or confirm the result of the student's investigation. The observations made should be recorded and preserved.

Roughly speaking, in about three-fourths of the cases natural delivery may be confidently expected. If so, the superintending officer should leave the student in charge. If he be fit to attend labour cases he may be trusted to tie the cord and express the placenta from the vagina.

If, on the other hand, the superintending officer finds that an ab normal condition is present, he should take the case under his own charge and treat it in the proper way.

The provision of an officer with such duties would secure the safety of the patients and the proper instruction of the students in practical midwifery. Such a system would not require of the superintending officer the waste of time in watching a natural process, which is the most irksome part of midwifery practice.

Such a system would recognize the essential fact of good midwifery practice, which is that prevention is better than cure. It would give the patients proper attendance, and I am sure that some such change would be welcomed by none more heartily than by the students. An intelligent student does not enjoy being left by the bedside of a patient com forted against dread of disaster only by the knowledge that most cases of labour would end happily if no doctor were there at all.

If medicine, surgery, and obstetrics are to remain as the "tripos" of medicine, something must be done-and that ere long-to render the teaching of the last named by no means so prominently the least attended to in the curriculum. Legislation is surely not here required to enforce an improved condition of things. Voluntary efforts on the part of the students and their teachers ought to produce, and that soon, what neither the suggestions nor stipulations of the General Medical Council, nor the regulations of the Examining Boards have hitherto grasped.

Gentlemen, I must apologise for these somewhat desultory remarks, and trust that I have not been too academical. I have only further to thank you for your attention, and once 
more for the honour you have conferred upon me by placing me in this chair.

\section{REFERENCES.}

1 Lancet, January gth, 1904, p. 113. 2 Lancet, Milroy Lecture, June 18th, 904. 3 Dr. Sinclair's letter. BRITISH MEDICAL JoURNAL, June 4th, 1904 p 134r. 2 Lecture on the Midives Act, 1902, and the Teaching of Midwirery to Students of Medicine, Adaress at Owens College, April, 1903 vol. Ivi, p. 39r. 6 BRITISH MEDICAL JoURNAL, Januarv gth, s9o4, p. 76.

\section{MEMORANDA : \\ MEDICAL, SURGICAL, OBSTETRICAL, THERA- PeUtical, Pathological, Etc.}

MITRAL STENOSIS IN ADVANCED LIFE. As mitral stenosis at an advanced age is rare, the two followjng cases which have recently been noted in the Sick Asylum, The Hyde, Hendon, N.W., may be of interest :

The first case was that of J. M., aged 73 , who was admitted on September 17th, 1903, complaining of pain in the leit side and dyspnoea. As she was very deaf the duration of the cardiac trouble was difficult to ascertain. Upon examination there was felt a slight apical thrill, and a well-marked presystolic murmur in the mitral area was audible. The patient gradually went downhill, and difd on April 9th, 1904. At the necropsy an advanced degree of stenosis of the mitral valveof the "button-hole" type-was found, and there was a row of pale vegetations on the edge of the orifice. There was an old infarct in the spleen. The leit auricle was much dilated.

The second case was as follow: : ' $\mathrm{Y}$. Y., aged 73, was admitted on March 2ist, 1904, complaining of cough and emaciation. No murmur of the heart could be detectod, but the lungs showed signs of general bronchitis. On May 29th signs of consolidation at the right apex were present. He grew rapidly worse, and died on June $6 \mathrm{th}, 19 \mathrm{c} 4$. At the necropsy there was found a moderate degree of stenosis of the mitral orifice, of the funnel type, and a row of old vegetations at one part of the edge of the opening. The orifice was just wide enough to allnw the little finger to pass through. Numerous tuberculous deposits were present in both lungs, with a few old cavitieg.

The second case is also interesting from the co-existence of pulmonary tuberculnsis with organic mitral disease.

JoHn S. F. WEIR, M.B., B.Ch.(R.U.I.).

Sick Asylum, The Hyde, Hendon, N.W.

\section{POISONING BY "FOOL'S PARSLEY" (AETHUSA} CYNAPIUM).

ON July ist, 1904, I received a message to attend E. W., aged 23, domestic servant, and found her to be suffering from severe abdominal pains with persistent vomiting and diarrhoea. The vomited matter was green stained. The patient was extremely collapsed. Surface cold, radial pulse absent, heart beating at the rate of 120 times a minute, heart sounds very feeble. The temperature was so subnormal as to be incapable of being registered by the ordinary clinical thermometer-the mercury not rising to the $95^{\circ} \mathrm{F}$. graduation mark. On inquiry I elicited the fact that on the previous day the patient had eaten a considerable quantity of a herb gathered in the kitchen garden attached to the house, which she believed to be "mustard and cress." This proved to be "fool's parsley" (Aethusa cynapium) of very young growth. The symptoms of poisoning did not come on until some twenty hours after ingestion.

Morphine (for the pain) and stimulants were administered, and the patient made a speedy recovery.

Monkseaton, Northumberland. H. E. Davison, M.D.

DIPHTHERIA AND HOFMANN'S BACILLUS. THe view appears to be gaining . ground that Hofmann's bacillus and the true diphtheria bacillus are in no way related to one another, and it is right that pieces of evidence, however small, should be brought forward in order that this important point should be cleared ap. I therefore venture to record the following memoranda of an outbreak of infection with Hofmann's bacillus, coincident with what appeared to be an isolated case of true diphtheria.

Three or four years ago I was resident at a London Children's Hospital where the excellent practice was observed of taking $s$ wabs of the throats of all patients admitted to the waj ds and submitting the same to the Jenner Institute for examinition. On one occasion I admitted a patient from whose throat a culture of Hofmann's bacillus was obtained. From the throats of none of the other children at that time in the ward was either Hofmann's or the true diphtheria bacillus isolated. A week later a case of clinically true diphtheria, from which the true diphtheria bacillus was isolated, occurred in the ward. I then again took cultures from the throats of the other patients, of whom six, out of a total of eight, yielded cultures of Hofmann's bacillus. No further cases of diphtheria developed, and a few days later swabs again taken from the six patients proved to be sterile.

It would be interesting to learn if a similar sequence of events has been observed elsewhere, for coincidences are of such frequent occurrence in medicine, that unless repeated on several occasions no value can be attached to them

Torquay.

A. E. Carver, M.D., M.R.C.P.

\section{THE EFFICACY OF VACCINATION TESTED BY} INOCULATION AND SMALL-POX.

Dr. T. D. AclaND, in an address delivered on March 22nd, 1902, on "Vaccination and Common Sense," states that the means which might be adopted for deciding the question as to whether vaccination protects against small-pox are:

r. By vaccinating first, and inoculating with small-pox afterwards, a test which cannot, of course, be made in the present day.

2. By observing the effect of vaccination on particular groups of persons exposed to the contagion of small. pox under more or less. imilar conditions.

3. By observing the comparative frequency with which small-pox attacks the vaccinated and unvaccinated in large communities, the degree of the severity of the attack in each of these classes, and the resulting death.rate.

4. By observing the effect of vaccination upon the age at which smallpox is most prevalent amongst those who have been vaccinated in infancy and among those who have not.

The present communication aims at supplying evidence mainly under the first head - a method of testing the efficacy of vaccination which is not available in countries where inoculation is forbidden by law. In Burmah, where I have been engaged in Government Medical Service for the past ten years. inoculation is freely practised outside the limits of municipa towns and is not forbidden by law. It is a common experience, where small-pox is epidemic, to find that the local sayco. (medicine man) has been busy in a village inoculating all children who have not been protected by a previous attack of the disease. The method adopted is to select a mild case: pick off a few scabs from the pustules, grind these as fine as possible, mix the powder with water and inject some of the mixture into the forearm or rub it into punctures about 3 in. or 4 in. above the wrist.

In April, 1902, I received information that small-pox had broken out in a village called Leyamah, Pakokku District. On reaching the village I found that 59 persons had been attacked; that 22 of these, chiefly children, had got the disease by infection, and the rest-namely, 37 children-by inoculation. There were 5 deaths -1 man, who had been. infected, and 4 children, who are said not to have been inoculated. The total population of the village was about 1,500 . I also found that isolation had in no way been practised. The headman of the village informed me that not a single vaccinated child had been infected, and that the vaccinated children that had been inoculated were also free from the disease, but that all unvaccinated children had been inoculated successfully. After personal inspection of each child vaccinated in 1900 and 1901 , and also of all those inoculated, I made the following notes:

Number of children successfully vaccinated in rgco and rgor

Number successfully vaccinated, inoculated mithout result

umber successfully vaccinated and have resisted infection, but were not inoculated

Thus not a single child successfully vaccinated a year or two previously got small-pox either by infection or inoculation. The headman further informed me-and I verified the fact-that his six children had all been inoculated, that four of these had been successfully vaccinated and resisted inoculation, and were free of the disease, while the remaining two that had not been protected got.a mild attack of small-pox.

From Leyamah I proceeded to a village called Pyintha where I found that there had been 8 cases of small pox, that: all the vaccinated children (14) had resisted infection, and that one of these had been inoculated without $\mathrm{f}$ ffect.

In Burmah, as in some parts of this country, vaccination is not popular, and such was the attitude of the majority in the Leyamah village till the people had satisfied themselves by as severe a test as nossible. The hesdman admitted that he was ${ }^{1}$ BRITISH MEDICAI JOURNAL, A pril 26th, 1902, pp. $2009-16$; 